\title{
Infection and coronary heart disease
}

\author{
R. W. ELLIS \\ Department of Clinical Bacteriology, University Hospital NHS Trust, Queen Elizabeth Medical Centre, \\ Edgbaston, Birmingham B15 2TH
}

\begin{abstract}
A large body of evidence exists that implicates a number of microbial agents in the pathogenesis of coronary heart disease (CHD). This, if proven, may have far-reaching implications for the prevention and treatment of CHD and other atherosclerotic disease. The histopathology of atherosclerosis and its natural history suggest infectious causation at many points along the progression of disease, particularly with regard to $\mathrm{CHD}$, and a number of pathogens have been the focus of study. Viral agents implicated include Coxsackie $B_{4}$ virus, for which tenuous sero-epidemiological associations exist, and the Herpesviridae. The animal herpesvirus causing Marek's disease in chickens causes atherosclerotic lesions in these animals. Herpes simplex virus I and II have been found in aortic smooth muscle and produce changes in vitro in smooth muscle that are similar to those seen at the beginning of atherosclerosis and which may also explain some of the features of atherosclerotic complications. Cytomegalovirus is implicated more strongly sero-epidemiologically by in-vivo detection in atherosclerotic lesions and by its links with post-cardiac transplant vasculopathy - a syndrome similar to atherosclerosis. Bacteria have also been shown to have links with CHD. Chlamydia pneumoniae and Helicobacter pylori have both been associated sero-epidemiologically with $\mathrm{CHD}$, and these findings have been consolidated by recent work showing their presence in atherosclerotic lesions in adults. Bacterial infections in general lead to many changes in lipid, thrombic and other acute-phase protein metabolism, and some of these changes occur with both $C$. pneumoniae and $H$. pylori infections. The ubiquity and similar epidemiological features to CHD of all these microbial pathogens make the resolution of the causative issue impossible by retrospective means. All that can be shown at present are a variety of weak and strong links, the significance of which can only be determined by large and perhaps lifetime prospective studies.
\end{abstract}

\section{Introduction}

Infectious agents are now being implicated more frequently as causes of diseases that have been considered previously to be of non-infectious aetiology. Spurred on by the most well-known examples (e.g., Helicobacter pylori and peptic ulceration), modern research is uncovering more such associations, ranging from the tenuous to the tenacious. Coronary heart disease (CHD) is a case in point. The benefits derived from elucidating infectious factors in this disease state could be enormous if prevention of transmission or microbial cure were achieved. To date, a large amount of factual data points a suspicious finger at several pathogens in the aetiology of CHD; but how convincing is the evidence and, if infectious agents are shown

Received 6 Sept. 1996; revised version accepted 19 Nov. 1996.

Corresponding author: Dr R. W. Ellis. to have a role in CHD, how important is that role and, more importantly, can CHD thereby be rendered preventable or curable?

\section{Atherosclerosis}

Atherosclerosis is the main pathological process involved in CHD and is, logically, the first place to look for infectious aetiology. The process of atherosclerosis itself provides the first hints of potential infectious cause, with its characteristic inflammatory cell infiltrate in the lipid streaks seen in some children and young adults. 'Foamy' macrophages feature prominently in these early lesions, which seem to be progenitor lesions of the atherosclerotic process. Smooth muscle proliferation, with subsequent intimal thickening, luminal narrowing and endothelial degeneration constitute the natural history of atherosclerosis, with the severity and speed of these changes being 
influenced by factors that include smoking, hypertension, diabetes, dyslipidaemias and age. Not all atherosclerotic lesions progress through this full spectrum of disease but, in severe cases, the changes outlined above may lead to thrombosis, embolus or degrees of ischaemia that result in the clinical manifestations of acute or chronic coronary heart disease. Of course, arteries other than the coronary vessels can be affected, giving rise to different clinical syndromes, but for simplicity this review will deal only with the coronary vasculature.

\section{Early predisposing events}

What factor (or factors) begins this series of events in early childhood when the first histological changes become apparent? The inflammatory nature of the early cellular infiltrate suggests that either infection or autoimmune phenomena, or a combination thereof, are avenues to explore, with viruses, bacteria and nonviral obligatory intracellular parasites all being implicated as potential precipitants of the atherosclerotic process. At the other end of the disease's progression is the possibility of infection acutely triggering myocardial infarction (MI). Recent febrile illness has been associated significantly with MI [1], and viral infection can produce an acute coronary arteritis [2]. Add to this the coronary vasculitic and aneurysmal changes pathognomonic of Kawasaki disease (which may ultimately prove to be infectious in origin [3]), and infection may be seen as having at least two possible main pathogenetic portals into the natural history of CHD.

\section{Viruses}

\section{Cardiotropic viruses}

Cardiotropic viruses were first implicated in the pathogenesis of CHD in 1968 when experimental Coxsackie $\mathrm{B}_{4}$ virus infection in mice was shown to produce acute coronary arteritis [4]. Encouraged by this finding, and the report of MI occurring in two normolipidaemic male patients following a recent unknown viral illness [2], other investigators sought a link between Coxsackie B virus and CHD [5-8]. The lack of control groups in those studies supporting a link $[5,6]$, and the absence of an association in those studies which were controlled adequately $[7,8]$, led to a falling-off of interest in this particular virus and acute MI. Nevertheless, the stage was set for further investigations.

\section{Herpesviridae}

It is perhaps surprising that members of the family Herpesviridae, not classically considered as cardiotropic, should emerge as candidates for the initiation (and perhaps the evolution) of atherosclerosis. Some viruses cause tissue lesions which are monoclonal in nature. This may be caused, in part, by transforming abilities that can be seen in cell lines infected by viruses such as Rous sarcoma virus and the Papova virus grouping. What is unusual is the finding that the smooth muscle cells in atherosclerotic plaques are monoclonal in nature [9], thus implying that atherosclerotic plaques may be considered as vascular tumours. This has several implications for theories exploring the initiation of atherosclerosis, not least of which is that of a viral causation. Obvious candidates would be those viruses whose ubiquity equals that of atherosclerosis and those that exhibit transforming abilities. The herpesviruses are a highly prevalent family of viruses, and some of their members affecting man have been shown to possess transforming abilities (e.g., herpes simplex virus (HSV) II, cytomegalovirus (CMV) and EpsteinBarr virus). Other members of the family have been implicated strongly in the aetiology of tumours (e.g., human herpesvirus VIII and Kaposi's sarcoma virus). Marek's disease virus, a herpesvirus causing disease in chickens, has been shown to cause coronary artery atherosclerosis in these animals [10]. This has focused research on the more familiar members of the herpesvirus family. HSV genomic material has been demonstrated by in-situ hybridisation in smooth muscle cells of normal and abnormal aortic tissue obtained at coronary bypass surgery from patients with atherosclerosis [11]. Of further interest is the fact that the genomic material detected was mRNA, suggesting that the viruses detected were not merely latent cellular passengers but were actively replicating pathogens. Similar findings occurred in a study of arterial tissues of young trauma victims [12].

Further evidence solidifying the role of HSV in atherosclerosis is lacking, but CMV, another herpesvirus, has been implicated more strongly as a potential atherogenic agent. The earliest evidence comes from in-situ hybridisation techniques that demonstrated CMV-specific nucleic acid sequences in cells derived from advanced atherosclerotic plaques [13]. This evidence was followed by electron microscopic demonstration of herpesviruses in atheromatous tissue [14]. The association was strengthened further by the demonstration with in-situ dot-blot hybridisation, and the detection by polymerase chain reaction (PCR), of whole CMV genomes in coronary arteries of patients with severe atherosclerosis $(90 \%$ of samples as compared with $50 \%$ of samples from patients with mild or no atherosclerosis in one study [15]). More recently, CMV nucleic acid sequences have been detected in early lesions of atherosclerosis in young trauma victims without symptomatic disease [12] (found in tandem with HSV in this study), and CMV-specific proteins have been detected in smooth muscle cells cultured from segments of coronary artery which have restenosed following angioplasty [16]. CMV seropositivity has also been classified as a risk factor for pre-transplant coronary atherosclerosis 
in the younger age groups of a cardiac transplant population studied in the USA [17]. However, crucially, efforts to find evidence of active CMV replication within atheromatous tissue (CMV-specific mRNA detection by PCR) have so far met with little success [18]. Lastly, CMV may also be a significant factor in post-transplant arteriopathic changes. Cardiac allograft vasculopathy (CAV) is a post-cardiac transplant phenomenon which, by affecting the coronary arteries of the transplant, can cause substantial posttransplant morbidity and mortality. $\mathrm{CAV}$ resembles 'conventional' coronary atherosclerosis at many points of its histopathological spectrum, apart from its rapidity of development [19], and active CMV infection occurring post-transplant has been associated with CAV in the clinical setting [20-22].

So the evidence of a role for herpesviruses in CHD has accumulated in the patient setting, but the ubiquity of these viruses makes interpretation of clinically based studies difficult. However, molecular evidence is available. The expression of receptors seen in vitro on HSV-infected cells, which are capable of binding monocytes [23], in theory may be significant in the early stages of atherosclerosis when 'foamy' macrophages (essentially lipid-accumulating monocytes) appear in the media of the vessel wall. In the laboratory, HSV can infect fetal smooth muscle cells [11] and has been seen to promote accumulation of cholesteryl esters and lipids in the same cells in culture [24]. In addition, HSV may cause some of the pathology that occurs relatively late in the atherosclerotic process. Atherosclerotic plaques may become thrombosed, leading to MI and other phenomena such as cerebrovascular accidents. HSV may enhance thrombus formation by virtue of the propensity of infected cells to bind platelets in vitro and generate thrombin [25]. Finally, if the monoclonal smooth muscle proliferation seen in atherosclerosis is considered as a benign tumour, then the presence of a transforming principle [26] in extracts obtained from atherosclerotic plaques assumes great significance for a viral aetiology.

\section{Bacteria}

Bacteria have also featured prominently in the search for infectious causes of $\mathrm{CHD}$ and two recently discovered pathogens are at the centre of ongoing research efforts.

\section{Chlamydia pneumoniae}

C. pneumoniae, a member of the family Chlamydiaceae, causes lower and upper respiratory tract infection, conjunctivitis, and has been implicated in the aetiology of endocarditis, sarcoidosis and asthma [27]. Controlled sero-epidemiological studies conducted in Finland in the late 1980s showed an association between the presence of $\operatorname{IgG}$ and $\operatorname{IgA}$ to $C$. pneumoniae and a diagnosis of angina pectoris [28]. Furthermore, the association between the presence of anti-chlamydial IgM and acute myocardial infarct (AMI) suggested that recent primary infection or reactivated infection might predispose to AMI [28]. Further evidence has since accumulated from sero-epidemiological studies in Finland [29] and other countries [30-32], and direct evidence of the presence of $C$. pneumoniae in atherosclerotic lesions from healthy young South African adults has also been acquired via PCR, immunocytochemical staining and electron microscopy [33]. In the later sero-epidemiological studies, confounding risk factors (e.g., smoking) were discounted by statistical methods. However, epidemiological discrepancies still exist. Perhaps the most major of these is the high seroprevalence of antibodies to $C$. pneumoniae in peri-equatorial countries where CHD is not a major public health problem [34]. Clearly, this discrepancy needs to be resolved as part of ongoing research efforts.

\section{Helicobacter pylori}

H. pylori may yet be able to add another 'noninfectious' disease to its trophy cabinet. Features common to the epidemiology of peptic ulceration and CHD have prompted several sero-epidemiological studies that confirmed the presence of an association which seems, statistically speaking, unrelated to other risk factors common to the two disease states [32, 35]. Recent work has demonstrated for the first time the presence of $H$. pylori and $C$. pneumoniae genomic material in the coronary arteries of myocardial infarct cases at autopsy [36].

\section{Association with CHD}

The explanation of the associations between CHD and these bacterial infections remains hidden. The presence of confounding common risk factors seems to have been neutralised by statistical methods for both $C$. pneumoniae and $H$. pylori. What remains now is to elucidate whether the associations are causal or not. A causative concept is not as fanciful as it seems initially. Bacterial infection may lead to molecular sequelae that might have effects on the initiation and maintenance of the atherosclerotic process. Of particular interest are the changes in lipid metabolism observed during gramnegative sepsis. Both serum triglyceride and very lowdensity lipoprotein (VLDL) levels increase during the acute phase of gram-negative sepsis in man, with levels of low-density lipoprotein (LDL)-cholesterol and highdensity lipoprotein (HDL) decreasing concomitantly [37]. During infection there is also a tendency for the plasma to move towards a hypercoagulable state, with plasma clotting factors increasing in concentration, increased procoagulant activity at the level of the vascular endothelium, and a shifting of prostaglandin metabolism towards thrombosis [38-40]. Increased 
adhesion of circulating leucocytes to the vascular endothelium also occurs and, in the case of gramnegative infection, the endothelium is damaged directly by lipopolysaccharide [38]. Lipopolysaccharide also affects circulating and tissue macrophages, increasing their production of free radicals. Free radicals are known to oxidise LDL, the product of which (oxidised LDL), has been shown to transform macrophages into foam cells, which are known to be important in the pathogenesis of atherosclerosis [38].

Whether these events occur in $C$. pneumoniae and $H$. pylori chronic infection remains to be seen. Furthermore, is there a role for these potentially predisposing events in atherogenesis and acute ischaemic episodes? Some of the acute-phase proteins may offer at least a partial answer. When present in raised concentrations in human plasma, fibrinogen has been shown to be a risk factor for CHD, and individuals seropositive for $C$. pneumoniae and $H$. pylori have been shown to possess chronically elevated levels of fibrinogen [41, 42]. More recently, C-reactive protein (CRP), another acute-phase protein, has been shown to correlate with poor prognosis in unstable angina [43] and with prevalence of indirect evidence of CHD [44] when present at levels approaching the upper limit of normal. Whether high levels of acute-phase proteins mean inflammation is involved in the pathogenesis of CHD, or simply that chronically stressed myocardium produces a mild acute inflammatory response remains to be resolved.

\section{Conclusions}

In summary, the evidence for infectious causation of CHD is, at present, only circumstantial and extremely weak in some cases. The high prevalence of most of the pathogens mentioned may make it impossible to prove a causal link in retrospective studies, and prospective studies must reach adequate sizes to accommodate the many epidemiological variables that are common to potential pathogens and the process of CHD. Nevertheless, the accumulated data suggest that the issue should be resolved by further research efforts. Already, appropriate funding is being provided by certain research bodies that recognise this need. Ultimately, it could be that CHD and other atherosclerosis-based disease can be sent the way of peptic ulceration with a simple course of antibiotics or even a childhood vaccination.

\section{References}

1. Spodick DH, Flessas AP, Johnson MM. Association of acute respiratory symptoms with onset of acute myocardial infarction: prospective investigation of 150 consecutive patients and matched control patients. Am $J$ Cardiol 1984; 53: 481-482.

2. Burch GE, Shewey LL. Viral coronary arteritis and myocardial infarction. Am Heart $J$ 1976; 92: 11-14
3. Abe J, Kotzin BL, Jujo $\mathrm{K}$ et al. Selective expansion of $\mathrm{T}$ cells expressing T-cell receptor variable regions $\mathrm{V} \beta 2$ and $\mathrm{V} \beta 8$ in Kawasaki disease. Proc Natl Acad Sci USA 1992; 89: 4066-4070.

4. Sohal RS, Burch GE, Chu KC, Leiderman E, Colcolough HL. Ultrastructural changes in cardiac capillaries of Coxsackie $\mathrm{B}_{4}$ infected mice. Lab Invest 1968; 19: 399-405.

5. Nicholls AC, Thomas $M$. Coxsackie virus infection in acute myocardial infarction. Lancet 1977; 1: 883-884.

6. Woods JD, Nimmo MJ, Mackay-Scollay EM. Acute transmural myocardial infarction associated with active Coxsackie virus B infection. Am Heart $J$ 1975; 89: 283-287.

7. Wood SF, Rogen AS, Bell EJ, Grist NR. Role of Coxsackie B viruses in myocardial infarction. Br Heart $J$ 1978; 40: $523-525$.

8. O'Neill D, McArthur JD, Kennedy JA, Clements G. Coxsackie $\mathrm{B}$ virus infection in coronary care unit patients. $J$ Clin Pathol 1983; 36: 658-661.

9. Benditt EP, Benditt JM. Evidence for a monoclonal origin of human atherosclerotic plaques. Proc Natl Acad Sci USA 1973; 70: $1753-1756$.

10. Fabricant CG, Fabricant J, Minick CR, Litrenta MM Herpesvirus-induced atherosclerosis in chickens. Fed Proc 1983; 42: 2476-2479.

11. Benditt EP, Barrett T, McDougall JK. Viruses in the etiology of atherosclerosis. Proc Natl Acad Sci USA 1983; 80: 6386-6389.

12. Yamashiroya HM, Ghosh L, Yang R, Robertson AL. Herpesviridae in the coronary arteries and aorta of young trauma victims. Am J Pathol 1988; 130: 71-79.

13. Petrie BL, Melnick JL, Adam E, Bureck J, McCollum CH, DeBakey ME. Nucleic acid sequence of cytomegalovirus in cells cultured from human arterial tissue. J Infect Dis 1987; 155: $158-159$.

14. Gyorkey F, Melnick JL, Guinn GA, Gyorkey P, DeBakey ME Herpesviridae in the endothelial and smooth muscle cells of the proximal aorta of atherosclerosis patients. Exp Mol Pathol 1984; 40: 328-339.

15. Hendricks MGR, Salimens MMM, Vauboven CPA, Bruggeman CA. High prevalence of latently present cytomegalovirus in arterial walls of patients suffering from grade III atherosclerosis. Am J Pathol 1990; 136: 23-28.

16. Speir E, Modali R, Huang E-S et al. Potential role of human cytomegalovirus and p53 interaction in coronary restenosis. Science 1994; 265: 391-394.

17. Dummer S, Lee A, Breinig MK, Kormos R, Ho M, Griffith B. Investigation of cytomegalovirus infection as a risk factor for coronary atherosclerosis in the explanted hearts of patients undergoing heart transplantation. $J$ Med Virol 1994; 44: 305-309.

18. Kol A, Sperti G, Shani J et al. Cytomegalovirus replication is not a cause of instability in unstable angina. Circulation 1995; 91: $1910-1913$.

19. Ventura HO, Mehra MR, Smart FW, Stapleton DD. Cardiac allograft vasculopathy: current concepts. Am Heart J 1995; 129: $791-798$.

20. Normann SJ, Salomon DR, Leelachaikul $\mathrm{P}$ et al. Acute vascular rejection of the coronary arteries in human heart transplantation: pathology and correlations with immunosuppression and cytomegalovirus infection. $J$ Heart Lung Transplant 1991; 10: 674-687.

21. Koskinen PK, Nieminen MS, Krogerus LA et al. Cytomegalovirus infection and accelerated cardiac allograft vasculopathy in human cardiac allografts. $J$ Heart Lung Transplant 1993; 12: $724-729$.

22. Koskinen PK, Nieminen MS, Krogerus LA et al. Cytomegalovirus infection accelerates cardiac allograft vasculopathy: correlation between angiographic and endomyocardial biopsy findings in heart transplant patients. Transpl Int 1993; 6: 341-347.

23. Etingin OR, Silverstein RL, Friedman HM, Hajjar DP. Viral activation of the coagulation cascade: molecular interactions at the surface of infected endothelial cells. Cell 1990; 61: $657-662$.

24. Hajjar DP, Pomerantz KB, Falcone DJ, Weksler BB, Grant AJ Herpes simplex virus infection in human arterial cells: implications in atherosclerosis. $J$ Clin Invest 1987; 80: 1317-1321.

25. Visser MR, Tracy PB, Vercellotti GM, Goodman JL, White JG, 
Jacobs HS. Enhanced thrombin generation and platelet binding on herpes simplex virus-infected endothelium. Proc Natl Acad Sci USA 1988; 85: 8227-8230.

26. Penn A, Garte SJ, Warren L, Nesta D, Mindich B. Transforming gene in human atherosclerotic plaque DNA. Proc Natl Acad Sci USA 1986; 83: 7951-7955.

27. Marrie TJ. Chlamydia pneumoniae. Thorax 1993; 48: 1-4.

28. Saikku P, Mattila K, Nieminen MS et al. Serological evidence of an association of a novel chlamydia, TWAR, with chronic coronary heart disease and acute myocardial infarction. Lancet 1988; ii: $983-985$.

29. Saikku P, Leinonen M, Tenkanen L et al. Chronic Chlamydia pneumoniae infection as a risk factor for coronary heart disease in the Helsinki Heart Study. Ann Intern Med 1992; 116: $273-278$

30. Thom DH, Wang SP, Grayston JT et al. Chlamydia pneumoniae strain TWAR antibody and angiographically demonstrated coronary artery disease. Arterioscler Thromb 1991; 11: 547-551.

31. Thom DH, Grayston JT, Siscovick DS, Wang S-P, Weiss NS, Daling JR. Association of prior infection with Chlamydia pneumoniae and angiographically demonstrated coronary artery disease. JAMA 1992; 268: 68-72.

32. Patel P, Mendall MA, Carrington D et al. Association of Helicobacter pylori and Chlamydia pneumoniae infections with coronary heart disease and cardiovascular risk factors. $B M J$ 1995; 311: 711-714.

33. Kuo C-C, Shor A, Campbell LA, Fukushi A, Patton DL, Grayston JT. Demonstration of Chlamydia pneumoniae in atherosclerotic lesions of coronary arteries. J Infect Dis 1993; 167: 841-849.

34. Wang S-P, Grayston JT. Population prevalence of antibody to Chlamydia pneumoniae strain TWAR. In: Bowie WR, Caldwell $\mathrm{HD}$, Jones RP et al (eds) Chlamydial infections. Cambridge,
Cambridge University Press. 1990: 402-405.

35. Mendall MA, Goggin PM, Molineaux $\mathrm{N}$ et al. Relation of Helicobacter pylori infection and coronary heart disease. $\mathrm{Br}$ Heart $J$ 1994; 71: 437-439.

36. Cunningham A, Ward M, Matthews R, Ellis R. Helicobacter pylori and Chlamydia pneumoniae in tissues of myocardial infarction cases. 1st European Congress of Chemotherapy, Glasgow. 1996: Abstract W149.

37. Alvarez C, Ramos A. Lipids, lipoproteins, and apoproteins in serum during infection. Clin Chem 1986; 32: 142-145.

38. Lopes-Virella MF. Interactions between bacterial lipopolysaccharides and serum lipoproteins and their possible role in coronary heart disease. Eur Heart $J$ 1994; 14 Suppl K: $118-124$.

39. Nieminen MS, Mattila K, Valtonen V. Infection and inflammation as risk factors for myocardial infarction. Eur Heart $J$ 1993; 14 Suppl K: 12-16.

40. Reines HD, Halushka PV, Cook JA, Wise WC, Rambo W. Plasma thromboxane concentrations are raised in patients dying with septic shock. Lancet 1982; 2: 174-175.

41. Patel P, Carrington D, Strachan DP et al. Fibrinogen: a link between chronic infection and coronary heart disease. Lancet 1994; 343: 1634-1635.

42. Yarnell JWG, Baker IA, Sweetman PM et al. Fibrinogen, viscosity, and white blood cell count are major risk factors for ischemic heart disease. The Caerphilly and Speedwell collaborative heart disease studies. Circulation 1991; 83: 836-844.

43. Liuzzo G, Biasucci LM, Gallimore JR et al. The prognostic value of C-reactive protein and serum amyloid A protein in severe unstable angina. $N$ Engl J Med 1994; 331: 417-424.

44. Mendall MA, Patel P, Ballam L, Strachan D, Northfield TC. C reactive protein and its relation to cardiovascular risk factors: a population based cross sectional study. BMJ 1996; 312: $1061-1065$. 